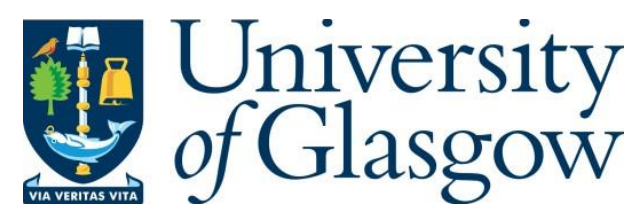

Rosnes, M. H., Mathieson, J. S., Törnroos, K. W., Johnsen, R. E., Cronin, L. and

Dietzel, P. D.C. (2019) Electrospray mass spectrometry investigation into the formation of CPO-27. Crystal Growth and Design, 19(4), pp. 2089-2096. (doi: 10.1021/acs.cgd.8b01657)

There may be differences between this version and the published version. You are advised to consult the publisher's version if you wish to cite from it.

http://eprints.gla.ac.uk/183834/

Deposited on: 18 July 2019

Enlighten - Research publications by members of the University of Glasgow http://eprints.gla.ac.uk 


\section{Article}

\section{An Electrospray Mass Spectrometry Investigation into the Formation of CPO-27}

Mali Husby Rosnes, Jennifer S. Mathieson, Rune E. Johnsen, Karl W. Törnroos, Leroy Cronin, and Pascal D. C. Dietzel

Cryst. Growth Des., Just Accepted Manuscript • DOI: 10.1021/acs.cgd.8b01657 • Publication Date (Web): 28 Feb 2019

Downloaded from http://pubs.acs.org on March 5, 2019

\section{Just Accepted}

"Just Accepted" manuscripts have been peer-reviewed and accepted for publication. They are posted online prior to technical editing, formatting for publication and author proofing. The American Chemical Society provides "Just Accepted" as a service to the research community to expedite the dissemination of scientific material as soon as possible after acceptance. "Just Accepted" manuscripts appear in full in PDF format accompanied by an HTML abstract. "Just Accepted" manuscripts have been fully peer reviewed, but should not be considered the official version of record. They are citable by the Digital Object Identifier (DOI@). "Just Accepted" is an optional service offered to authors. Therefore, the "Just Accepted" Web site may not include all articles that will be published in the journal. After a manuscript is technically edited and formatted, it will be removed from the "Just Accepted" Web site and published as an ASAP article. Note that technical editing may introduce minor changes to the manuscript text and/or graphics which could affect content, and all legal disclaimers and ethical guidelines that apply to the journal pertain. ACS cannot be held responsible for errors or consequences arising from the use of information contained in these "Just Accepted" manuscripts. 


\title{
An Electrospray Mass Spectrometry Investigation into the Formation of CPO-27
}

\author{
Mali H. Rosnes, ${ }^{*[a]}$ Jennifer S. Mathieson, ${ }^{[b]}$ Karl W. Törnroos, ${ }^{[a]}$ Rune E. Johnsen, ${ }^{[c]}$ Leroy \\ Cronin $^{[b]}$ and Pascal D. C. Dietzel ${ }^{*}[a]$
}

${ }^{[a]}$ Dr. Mali H. Rosnes, Prof. Karl W. Törnroos, Prof. Pascal. D. C. Dietzel, Department of Chemistry, University of Bergen. P.O. Box 7803, 5020 Bergen, Norway. E-mail:

Mali.Rosnes@uib.no; Pascal.Dietzel@uib.no. ${ }^{[b]}$ Dr. Jennifer S. Mathieson, Prof. Leroy Cronin, School of Chemistry, WestCHEM, University of Glasgow, Glasgow G12 8QQ, Lanark, Scotland. ${ }^{[\mathrm{c}]}$ Dr. Rune E. Johnsen, Department of Energy Conversion and Storage Technical University of Denmark, Frederiksborgvej 399, 4000 Roskilde, Denmark.

KEYWORDS Metal-Organic Frameworks (MOFs), Self-Assembly, Crystallisation, CPO-27-M, Electrospray ionisation mass spectrometry (ESI-MS), Time resolved PXRD.

ABSTRACT: Electrospray ionisation mass spectrometry (ESI-MS) has been utilised to investigate the self-assembly processes occurring during the formation of the microporous metal-organic framework CPO-27-M (M = Co, Ni). The mono- and dinuclear building units $\left\{\mathrm{M}\left(\mathrm{H}_{x} \mathrm{dhtp}\right)\right\}$ and $\left\{\mathrm{M}_{2}\left(\mathrm{H}_{x} \mathrm{dhtp}\right)\right\}$, where $\mathrm{H}_{x} \mathrm{dhtp}$ is the organic linker $\mathrm{H}_{x} \mathrm{C}_{8} \mathrm{O}_{6}$ and fragments thereof, were identified as key species present in the reaction mixture during the product formation. Time resolved powder X-ray diffraction analysis were used to follow the synthesis, and confirm that no other crystalline 
products occur in the reaction mixture prior to the crystallisation of CPO-27-Ni. When the reaction was performed at room temperature instead of the higher temperature of the solvothermal procedure, the compounds $\left[\left(\mathrm{M}\left(\mathrm{H}_{2} \mathrm{dhtp}\right)\left(\mathrm{H}_{2} \mathrm{O}\right)_{4} \cdot 2 \mathrm{H}_{2} \mathrm{O}\right](\mathrm{M}=\mathrm{Co}\right.$, Ni) crystallized instead of CPO27. It was confirmed that mono- and dinuclear species are key building blocks not only in the formation of CPO-27-M, but also in the formation of the $1 \mathrm{D}$ chain structure $\left(\mathrm{M}\left(\mathrm{H}_{2} \mathrm{dhtp}\right)\left(\mathrm{H}_{2} \mathrm{O}\right)_{4}\right)$ obtained from these room temperature reactions.

\section{INTRODUCTION}

Metal-organic frameworks (MOFs), also known as porous coordination polymers (PCPs), attract a lot of attention due to their crystalline, often porous, structures, associated with high specific surface areas. Permanently porous MOFs have been intensely studied over the last decades, with great promise for a diverse number of application areas. ${ }^{1-3}$ However, while a coherent understanding of the crystallisation process is of significant interest for the improved development of materials, studies of how these solids self-assemble in solution are scarce.

Over the last decades mass spectrometry (MS) has gained vast interest as a technique to investigate self-assembly processes, to study solution species, and to follow reactions over time gaining understanding on how reactions proceed, along with aiding in structure determination. ${ }^{4-5}$ Electrospray ionisation mass spectrometry (ESI-MS) has been used to investigate materials from silver coordination polymers to the self-assembly of metallodendrimers. ${ }^{6-7}$ It has also been used to confirm the structure of complex compounds and to investigate the self-assembly process in materials such as polyoxometalates (POMs) ${ }^{8-10}$ ESI-MS has been predicted to be a key tool in the further understanding of MOF formation. ${ }^{11}$

Whereas POMs are discrete nano-sized metal-oxide polyanions, MOFs are infinite hybrid networks. This results in very different behaviours than what is typically observed for POMs, such 
as poorer solubility, which makes it more challenging to carry out ESI-MS investigations of MOFs. A work-around for this problem was reported by Graibay et al., where they digested the MOFs, and used ESI-MS to identify and confirm the presence of multiple functional groups. ${ }^{12}$ There are also a few examples highlighting the potential in using ESI-MS and cryospray (temperature controlled) electrospray mass spectrometry (CSI-MS) to investigate the self-assembly processes occurring during the formation of zeolites and MOFs. ${ }^{11,13-19}$

Herein, we investigate the well-known isostructural series CPO-27-M, also denoted $\mathrm{M}_{2}(\mathrm{dhtp})$, $\mathrm{M}_{2}$ (dobdc) (dhtp/dobdc ${ }^{4-}=\mathrm{C}_{8} \mathrm{H}_{2} \mathrm{O}_{6}{ }^{4-}$ (2,5-dihydroxyterephthalate)) or M-MOF-74, where $\mathrm{M}=$ $\mathrm{Co}^{20}$ and $\mathrm{Ni}^{21}$ The structure is also formed with other divalent cations such as $\mathrm{M}=\mathrm{Mg},{ }^{22} \mathrm{Mn},{ }^{23}$ $\mathrm{Zn},{ }^{24} \mathrm{Fe},{ }^{25-26} \mathrm{Cu},{ }^{27-29}$ and $\mathrm{Cd} .{ }^{30}$ The CPO-27 series consists of a honeycomb like structure with hexagonal pores of roughly $1.2 \mathrm{~nm}$ in diameter. The chain composing the inorganic secondary building unit of the CPO-27-M structure is shown on top in Figure 1. The CPO-27-M series has been intensely studied due to the interesting structure, which contains an extraordinary high concentration of open metal sites, and potential in applications related to high storage capacity at lower pressures and high selectivity in gas sorption from gas mixtures. ${ }^{31-32}$ For instance, the CPO27-M series have been found to have exceptionally good $\mathrm{CO}_{2}$ adsorption properties, with CPO27-Mg reported with the highest $\mathrm{CO}_{2}$ capacity at 0.1 atm of all MOFs. ${ }^{33-34}$ However, the adsorption properties of the CPO-27-M compounds in general, and CPO-27-Mg in particular, are negatively affected under humid conditions. ${ }^{35}$ 

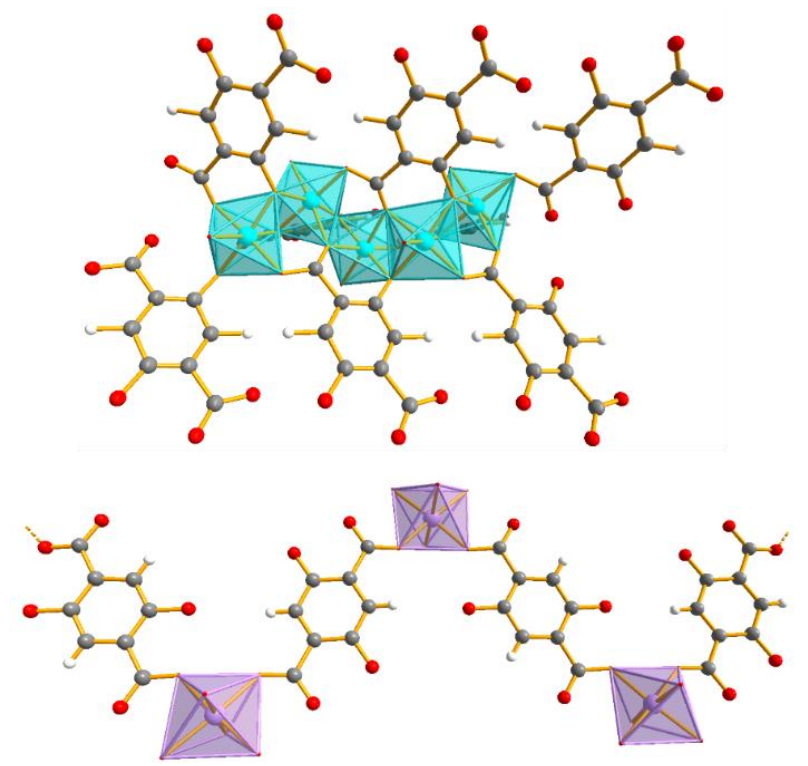

Figure 1. Top: Structure excerpt emphasising the inorganic secondary building unit of CPO-27$\mathrm{Ni}$, where all oxygen atoms of the dhtp ${ }^{4-}$ units are coordinated to nickel atoms so that a helical chain of condensed metal oxygen octahedra is formed. Bottom: The $1 \mathrm{D}$ chain structure of $\left[\left(\mathrm{M}\left(\mathrm{H}_{2} \mathrm{dhtp}\right)\left(\mathrm{H}_{2} \mathrm{O}\right)_{4} \cdot 2 \mathrm{H}_{2} \mathrm{O}\right](\mathrm{M}=\mathrm{Co}, \mathrm{Ni})\right.$, containing isolated metal oxygen octahedra. Nickel is shown in teal, cobalt in purple, carbon in grey, oxygen in red and hydrogen on benzene rings in white. Remaining hydrogen atoms, rotational disorder of benzene rings and non-coordinated water molecules are omitted for clarity.

A key to successfully realise the potential associated with MOFs lies in understanding their selfassembly process. ${ }^{36}$ Typically the syntheses of MOFs are carried out under solvothermal conditions. ${ }^{37-39}$ One of the reasons why the assembly of MOFs is not fully understood is due to the difficulties associated with directly analysing reaction mixtures in the experimental setups usually used to prepare MOFs, and due to the many parameters, such as temperature, pressure, reactant concentration and solvent system, that affect the synthetic conditions. However, a number of studies are available which discuss the crystallisation processes involved, usually using diffraction techniques, ${ }^{40-44}$ as well as a range of other techniques. ${ }^{14}$ However, it is challenging to establish a 
link between solid state and solution-based self-assembly. The formation of materials typically occurs via hydrolysis or condensation, ${ }^{36,45}$ with ligand exchange reactions playing a key role.

Herein, we investigate the synthesis of CPO-27-Ni and -Co by ESI-MS. The two members of the series were chosen because they can both be synthesised employing the same synthetic procedure, using THF and $\mathrm{H}_{2} \mathrm{O}$ as solvent, which is compatible with the requirements for the experimental conditions of the ESI-MS technique. Nickel containing species are easily identified in MS spectra due to its well-defined isotopic contribution to the MS peak-envelopes. This significantly aids in the identification of the species in the spectra. Cobalt on the other hand, does not have such a distinct isotope pattern, but by comparing peaks between $\mathrm{Ni}$ and Co spectra it can be used to confirm the peak assignments.

\section{EXPERIMENTAL DETAILS}

\section{Instrumentation}

Low resolution ESI-MS. The instrument used was an Agilent 6420A triple quadrupole (QqQ configuration) mass analyser using electrospray ionisation (ESI). It was connected to an Agilent 1200 series LC module (binary pump, column compartment/oven and auto sampler). The eluent stream was introduced directly into the source, at a dry gas temperature of $200^{\circ} \mathrm{C}$. The ion polarity for all MS scans recorded was positive, with the voltage of the capillary tip set at 3,500 V. Scan time was $500 \mathrm{~ms}$ and cell accelerator voltage was $7 \mathrm{~V}$. Fragmentor was at $120 \mathrm{~V}$ and $175 \mathrm{~V}$ for the starting materials, and at $175 \mathrm{~V}$ for the reaction mixtures. Initial experiments were also carried out in negative mode ESI-MS, however species from $\mathrm{H}_{4} \mathrm{dhtp}$ dominate these spectra, and no additional information regarding the speciation of $\mathrm{H}_{4} \mathrm{dhtp}$ with metal acetate were obtained. As a consequence we report only positive mode ESI-MS. Aliquots used for ESI-MS injections were 
diluted with $\mathrm{MeOH}$ or 1:9 (v:v) $\mathrm{H}_{2} \mathrm{O}$ and $\mathrm{MeOH}$ mixtures (to avoid formation of precipitate) to reach concentrations compatible with the MS (about $1 \cdot 10^{-2}$ to $1 \cdot 10^{-3} \mathrm{~mol} \mathrm{~L}^{-1}$ with respect to the original transition metal concentration).

High resolution ESI-MS. The MS apparatus used was a Bruker MaXis Impact instrument, calibrated using Agilent ESI-L tuning mix for the mass range m/z 100-3000. The eluent stream was introduced directly into the source, at a dry gas temperature of $200{ }^{\circ} \mathrm{C}$. The ion polarity for all MS scans recorded was positive, with the voltage of the capillary tip set at 4,800 V, end plate offset at $-500 \mathrm{~V}$, funnel 1 radio frequency (RF) at $400 \mathrm{Vpp}$ and funnel $2 \mathrm{RF}$ at $400 \mathrm{Vpp}$, hexapole RF at $100 \mathrm{Vpp}$, ion energy $5.0 \mathrm{eV}$, collision energy at $5 \mathrm{eV}$, collision cell RF at $200 \mathrm{Vpp}$, transfer time at $100.0 \mu$ s and the pre-pulse storage time at $1.0 \mu \mathrm{s}$. Aliquots used for ESI-MS injections were diluted with $\mathrm{MeOH}$ or 1:9 (v:v) $\mathrm{H}_{2} \mathrm{O}$ and $\mathrm{MeOH}$ mixtures (to avoid any precipitate formation) to reach MS compatible concentrations (about $1 \cdot 10^{-4}$ to $1 \cdot 10^{-5} \mathrm{~mol} \mathrm{~L}^{-1}$ with respect to the original transition metal concentration taking into the account the sensitivity of the instrument).

Powder X-ray diffraction. PXRD measurements were carried out on a Bruker AXS D8 Advance equipped with a 9 position sample changer. Data collection was performed using monochromatic $\mathrm{Cu} \mathrm{K}_{\alpha 1}$ radiation in Bragg-Brentano geometry.

Single Crystal X-ray diffraction. Suitable as-synthesised single crystals for diffraction experiments were mounted at ambient conditions in a minimum amount of Parabar 10312 oil (Hampton Research) in nylon loops. Intensity data was collected with a Bruker AXS TXS rotating anode system with an APEXII Pt ${ }^{135}$ CCD detector using graphite-monochromated Mo-K radiation $(\lambda=0.71073 \AA)$. CCDC 1499898 reference code contains the supplementary crystallographic data for this paper. These data can be obtained free of charge from The Cambridge Crystallographic Data Centre via www.ccdc.cam.ac.uk/data_request/cif. 
Synchrotron experiments. The X-ray diffraction experiment was performed at the SwissNorwegian Beamline (BM01A) at ERSF. A hot-air blower was programmed to heat the capillary containing the solution from room temperature to $110^{\circ} \mathrm{C}$ with a heating gradient of $5{ }^{\circ} \mathrm{C} \mathrm{min}^{-1}$. Diffraction data were collected during the heating using a MAR345 area detector. A wavelength of $0.7207 \AA$, a sample to detector distance of $300 \mathrm{~mm}$ with a slit size of $0.5 \times 0.5 \mathrm{~mm}$, and an exposure time of 20 seconds was used. This resulted in a time-resolution of 107.2 seconds per pattern (exposure time plus data readout time). The data were converted to normal onedimensional powder pattern using the program FIT2D. ${ }^{46}$

\section{Materials}

All chemicals, reagents and solvents were purchased from Sigma Aldrich and used as received without further purification.

\section{Synthetic methods}

Reactions carried out at $110^{\circ} \mathrm{C}$ :

\section{2:1 ratio of $\mathrm{M}(\mathrm{OAc})_{2} \cdot 4 \mathrm{H}_{2} \mathrm{O}\left(\mathrm{M}=\mathrm{Co}\right.$, Ni) and 2,5-dihydroxyterepthalic acid $\left(\mathrm{H}_{4} \mathrm{dhtp}\right)$.}

Either cobalt or nickel acetate tetrahydrate $(0.207 \mathrm{~g}, 0.833 \mathrm{mmol})$ was dissolved in $5 \mathrm{~mL} \mathrm{H}_{2} \mathrm{O}$ and the $\mathrm{H}_{4} \mathrm{dhtp}(0.083 \mathrm{~g}, 0.417 \mathrm{mmol})$ in $5 \mathrm{~mL}$ THF, before the reagents were mixed in a $23 \mathrm{~mL}$ Teflon insert. After stirring for $5 \mathrm{~min}$ the initial MS sample was taken, before the Teflon inserts were sealed in steel autoclaves and put in the oven at $110^{\circ} \mathrm{C}$. Several parallel reactions were set up simultaneously and stopped at different time intervals, from $30 \mathrm{~min}$ to $24 \mathrm{~h}$. The steel autoclaves were cooled to room temperature before they were opened and a sample for MS analysis were extracted by a micropipette. The solid products were obtained by filtration and washed with $\mathrm{H}_{2} \mathrm{O}$. 


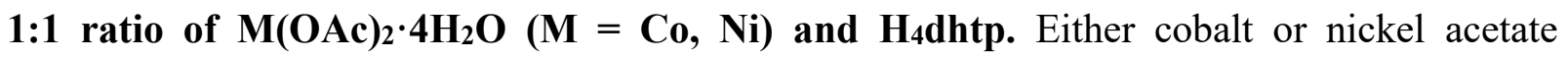
tetrahydrate $(0.207 \mathrm{~g}, 0.833 \mathrm{mmol})$ was dissolved in $5 \mathrm{~mL} \mathrm{H}_{2} \mathrm{O}$ and the $\mathrm{H}_{4} \mathrm{dhtp}(0.165 \mathrm{~g}, 0.833$ $\mathrm{mmol}$ ) in $5 \mathrm{~mL}$ THF, before the reagents were mixed in a $23 \mathrm{~mL}$ Teflon insert. After stirring for 5 min the initial MS sample was taken, before the Teflon inserts were sealed in steel autoclaves and put in the oven at $110^{\circ} \mathrm{C}$. Several parallel reactions were set up simultaneously and stopped at different time intervals, from $30 \mathrm{~min}$ to $24 \mathrm{~h}$. The steel autoclaves were cooled to room temperature before they were opened and a sample for MS analysis were extracted by a micropipette. The solid products were obtained by filtration and washed with $\mathrm{H}_{2} \mathrm{O}$.

\section{Reactions carried out at room temperature:}

These reactions were performed in glass vials, and the starting concentration of each of the reagents was kept constant. For all reactions the reagents were mixed in a glass vial and stirred for 5 min before the initial MS sample was taken and the vial sealed and left undisturbed. After about $48 \mathrm{~h}$ precipitate started forming. The products were collected by filtration and washed with $\mathrm{H}_{2} \mathrm{O}$.

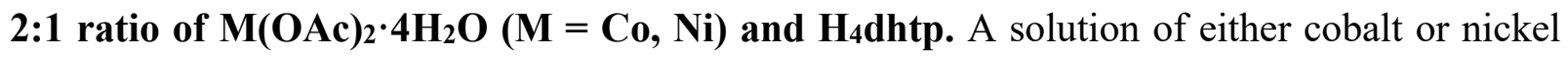
acetate tetrahydrate in $\mathrm{H}_{2} \mathrm{O}\left(0.167 \mathrm{~mol} \mathrm{~L}^{-1}\right)$ and a solution of $\mathrm{H}_{4} \mathrm{dhtp}$ in THF $\left(0.083 \mathrm{~mol} \mathrm{~L}^{-1}\right)$ were combined with a $v / v$ ratio of 1 .

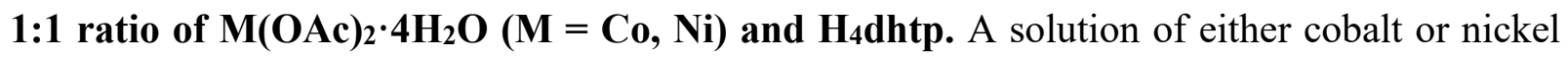
acetate tetrahydrate in $\mathrm{H}_{2} \mathrm{O}\left(0.167 \mathrm{~mol} \mathrm{~L}^{-1}\right)$ and a solution of $\mathrm{H}_{4} \mathrm{dhtp}$ in THF $\left(0.167 \mathrm{~mol} \mathrm{~L}^{-1}\right)$ were combined with a $v / v$ ratio of 1 .

Experiments details for time resolved PXRD experiment: A solution of $\mathrm{Ni}(\mathrm{OAc})_{2} \cdot 4 \mathrm{H}_{2} \mathrm{O}\left(3 \cdot 10^{-4}\right.$ $\mathrm{mol})$ in $1 \mathrm{~mL}$ of water and a solution of 2,5-dhydroxyterepthalic acid $\left(1.5 \cdot 10^{-4} \mathrm{~mol}\right)$ in $1 \mathrm{~mL} \mathrm{THF}$ were prepared. Equal volumes of each solution were combined into a $0.5 \mathrm{~mm}$ glass capillary. The capillary was flame sealed resulting in approximately equal volumes of liquid and gas phase, which 
corresponds to the conditions under the standard solvothermal synthesis of CPO-27-Ni. ${ }^{18}$ The capillary was glued onto the tip of a goniometer head. The diffraction experiment commenced approx. 30 minutes after mixing the solutions.

\section{RESULTS}

In this work, we investigate the MS results of the reaction mixtures before, during and after the formation of CPO-27-Ni and -Co. Firstly, we describe the MS analysis results of the starting materials, and secondly, of the initial reaction mixtures (before any solid product is observed). Thirdly, we follow the reactions at room temperature and at $110^{\circ} \mathrm{C}$ by ESI-MS, both before and during solid product formation. Finally, we relate the results of the ESI-MS and the synchrotron experiments.

Both CPO-27-Ni and -Co can be made using either 1:1 or 2:1 mixtures of $\mathrm{M}(\mathrm{OAc})_{2} \cdot 4 \mathrm{H}_{2} \mathrm{O}(\mathrm{M}=$ Co, Ni) and 2,5-dihydroxytherepthalic acid ( $\left.\mathrm{H}_{4} \mathrm{dhtp}\right)$, and both reaction set-ups are discussed herein. The solvent mixture used was a 1:1 (v:v) mixture of $\mathrm{H}_{2} \mathrm{O}$ and THF. Aliquots used for ESIMS injections were diluted with $\mathrm{MeOH}$ or $1: 9(v: v) \mathrm{H}_{2} \mathrm{O}$ and $\mathrm{MeOH}$ mixtures to reach MS compatible concentrations. The starting materials were extensively investigated by ESI-MS in advance to create a complete library of the species forming in solution in the absence of the reaction partner. Figure 2 shows a typical mass spectrum of $\mathrm{Ni}(\mathrm{OAc})_{2} \cdot 4 \mathrm{H}_{2} \mathrm{O}$ and $\mathrm{H}_{4} \mathrm{dhtp}$. The equivalent for $\mathrm{Co}(\mathrm{OAc})_{2} \cdot 4 \mathrm{H}_{2} \mathrm{O}$ and the corresponding assignments are shown in section $\mathrm{S} 2.1$ in the supporting information (SI). An overview of when different aliquots were taken is shown is scheme $\mathrm{S} 1$ in the $\mathrm{SI}$. For reactions at $110^{\circ} \mathrm{C}$ multiple reactions from the same stock solutions were set-up in parallel and stopped at different time intervals to obtain information about the evolution of the MS spectra with time. 

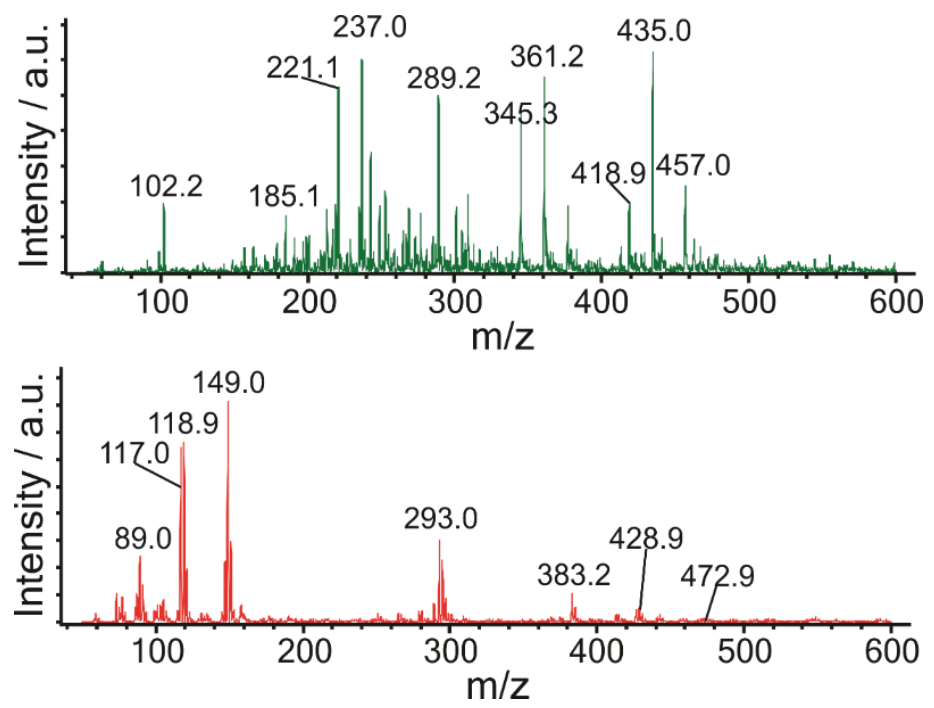

Figure 2. Typical MS spectra of $\mathrm{H}_{4} \mathrm{dhtp}$ (top) and $\mathrm{Ni}(\mathrm{OAc})_{2} \cdot 4 \mathrm{H}_{2} \mathrm{O}$ (bottom). See Figure $\mathrm{S} 2$ for $\mathrm{Co}(\mathrm{OAc})_{2} \cdot 4 \mathrm{H}_{2} \mathrm{O}$. The assignments are listed in Table S2. The result for $\mathrm{H}_{4} \mathrm{dhtp}$ is shown in Table $\mathrm{S} 1$. The species at $\mathrm{m} / z \mathrm{z} 18.9$ is assigned to $\left[\mathrm{Na}\left(\mathrm{CH}_{3} \mathrm{OH}\right)_{3}\right]^{+}$.

\section{Investigations into the initial mixtures}

$\mathrm{M}(\mathrm{OAc})_{2} \cdot 4 \mathrm{H}_{2} \mathrm{O}$ and $\mathrm{H}_{4}$ dhtp were dissolved in $\mathrm{H}_{2} \mathrm{O}$ and $\mathrm{THF}$, respectively, before they were mixed and stirred for less than $5 \mathrm{~min}$. No formation of solid product was observed at this point. An aliquot used for ESI-MS injections were diluted with $\mathrm{MeOH}$ or 1:9 (v:v) $\mathrm{H}_{2} \mathrm{O}$ and $\mathrm{MeOH}$ mixtures to reach MS compatible concentrations before being subjected to ESI-MS analysis.

New species are formed within the first minute after the two starting materials are mixed (which is the fastest time-scale we can measure on), as can be seen in the mass spectrum of the $\mathrm{Ni}(\mathrm{OAc})_{2} \cdot 4 \mathrm{H}_{2} \mathrm{O}$ and $\mathrm{H}_{4}$ dhtp mixture, shown in Figure 3, when compared with the individual starting materials in solution, shown in Figure 2. Assignments of the main species observed for both the Co and Ni reactions are listed in Table 1. Several species are identifiable as belonging to the solvent and the starting materials below $m / z 150$, but new species are also observed at higher $m / z$. The most evident are $m / z 236.9 / 237.9$, and 254.9/255.9, both assigned to $\left\{\mathrm{M}\left(\mathrm{H}_{x} \mathrm{dhtp}\right)\right\}$ species 
(where $\mathrm{H}_{x}$ dhtp represents $\mathrm{H}_{\mathrm{x}} \mathrm{C}_{8} \mathrm{O}_{6}$ and fragments thereof), see Table 1 for further details. The second most evident and intense species are observed at $\mathrm{m} / \mathrm{z} 370.9 / 372.9$ and $\mathrm{m} / \mathrm{z}, 430.9 / 432.9$, both assigned to $\left\{\mathrm{M}_{2}\left(\mathrm{H}_{x} \mathrm{dhtp}\right)\right\}$ species. For the Co-reactions $m / z$ 432.9, assigned to $\left\{\mathrm{M}_{2}\left(\mathrm{H}_{x} \mathrm{dhtp}\right)\right\}$ is sometimes almost equal in intensity to $\mathrm{m} / \mathrm{z} 255.9$. This is followed (in intensity) by species of typically significantly lower intensity assigned to $\left\{\mathrm{M}_{2}\left(\mathrm{H}_{x} \mathrm{dhtp}\right)_{2}\right\}, \quad\left\{\mathrm{M}_{3}\left(\mathrm{H}_{x} \mathrm{dhtp}\right)_{2}\right\}$ and $\left\{\mathrm{M}_{3}\left(\mathrm{H}_{x} \mathrm{dhtp}\right)_{3}\right\}$ complexes with solvent and/or acetate adducts.

There are some species with even higher $m / z$ present, but with significantly lower intensity, which we have successfully identified as species up to $\left\{\mathrm{M}_{4}\left(\mathrm{H}_{x} \mathrm{dhtp}\right)_{3}\right\}$ and $\left\{\mathrm{M}_{5}\left(\mathrm{H}_{x} \mathrm{dhtp}\right)_{4}\right\}$. This can be evidence of larger species being present in the solution. ${ }^{47}$

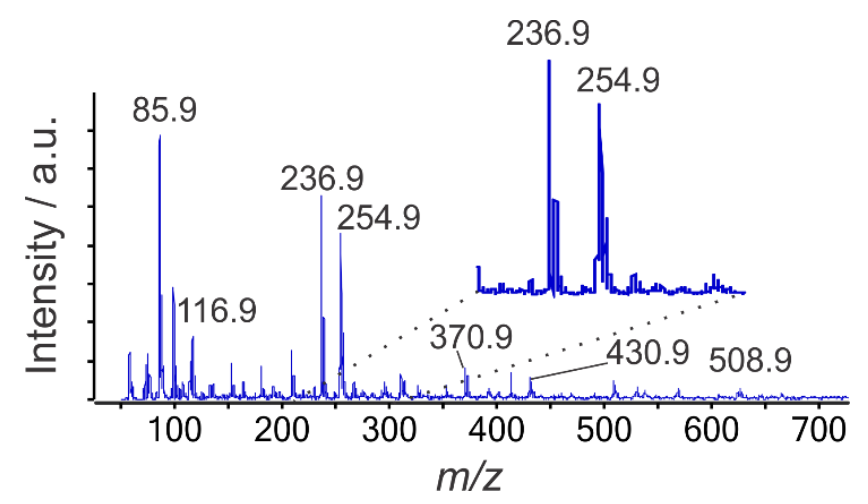

Figure 3. An example of a typical MS spectrum of the initial 1:1 molar ratio mixture of $\mathrm{Ni}(\mathrm{OAc})_{2}$ and $\mathrm{H}_{4} \mathrm{dhtp}$. The species found at $m / \mathrm{z} 236.9$ have been assigned to $\left[\mathrm{Ni}\left(\mathrm{C}_{8} \mathrm{H}_{3} \mathrm{O}_{5}\right)\right]^{+}$. 
Table 1. The most prominent species in the low resolution ESI-MS of the initial 1:1 mixture of $\mathrm{Ni}(\mathrm{OAc})_{2} \cdot 4 \mathrm{H}_{2} \mathrm{O}$ with $\mathrm{H}_{4} \mathrm{dhtp}$ (left) and $\mathrm{Co}(\mathrm{OAc})_{2} \cdot 4 \mathrm{H}_{2} \mathrm{O}$ with $\mathrm{H}_{4}$ dhtp (right).

\begin{tabular}{ccc}
\hline $\begin{array}{c}\boldsymbol{m} / \boldsymbol{z} \\
(\mathbf{M}=\mathbf{N i})\end{array}$ & Assigned to & $\begin{array}{c}\boldsymbol{m} / \boldsymbol{z} \\
(\mathbf{M}=\mathbf{C o})\end{array}$ \\
236.9 & {$\left[\mathrm{M}\left(\mathrm{C}_{8} \mathrm{H}_{3} \mathrm{O}_{5}\right)\right]^{+}$} & 237.9 \\
254.9 & {$\left[\mathrm{M}\left(\mathrm{C}_{8} \mathrm{H}_{5} \mathrm{O}_{6}\right)\right]^{+}$} & 255.9 \\
286.9 & {$\left[\mathrm{M}\left(\mathrm{C}_{8} \mathrm{H}_{5} \mathrm{O}_{6}\right)\left(\mathrm{CH}_{3} \mathrm{OH}\right)\right]^{+}$} & 287.9 \\
292.8 & {$\left[\mathrm{M}_{2}\left(\mathrm{CH}_{3} \mathrm{COO}\right)_{3}\right]^{+}$} & 294.9 \\
370.9 & {$\left[\mathrm{M}_{2}\left(\mathrm{C}_{8} \mathrm{H}_{4} \mathrm{O}_{6}\right)\left(\mathrm{CH}_{3} \mathrm{COO}\right)\right]^{+}$} & 372.9 \\
430.9 & {$\left[\mathrm{M}_{2}\left(\mathrm{C}_{8} \mathrm{H}_{5} \mathrm{O}_{6}\right)\left(\mathrm{CH}_{3} \mathrm{COO}\right)_{2}\right]^{+}$} & 432.9 \\
452.9 & {$\left[\mathrm{M}\left(\mathrm{C}_{8} \mathrm{H}_{5} \mathrm{O}_{6}\right)\left(\mathrm{C}_{8} \mathrm{H}_{6} \mathrm{O}_{6}\right)\right]^{+}$} & 453.9 \\
508.9 & {$\left[\mathrm{M}_{2}\left(\mathrm{C}_{8} \mathrm{H}_{4} \mathrm{O}_{6}\right)\left(\mathrm{C}_{8} \mathrm{H}_{5} \mathrm{O}_{6}\right)\right]^{+}$} & 510.9 \\
\hline
\end{tabular}

${ }^{[\mathrm{a}]}$ For a complete list of species and assignments, see Table S3 and Table S4 for Ni and Co, respectively.

When comparing the results for $\mathrm{Ni}$ and $\mathrm{Co}$, it is evident that species coming from $\mathrm{Co}(\mathrm{OAc})_{2} \cdot 4 \mathrm{H}_{2} \mathrm{O}$ are of higher relative intensity compared to those coming from $\mathrm{Ni}(\mathrm{OAc})_{2} \cdot 4 \mathrm{H}_{2} \mathrm{O}$. This can be either because $\mathrm{Co}(\mathrm{OAc})_{2} \cdot 4 \mathrm{H}_{2} \mathrm{O}$ is easier to ionise compared to $\mathrm{Ni}(\mathrm{OAc})_{2} \cdot 4 \mathrm{H}_{2} \mathrm{O}$ or that it takes longer for species between $\mathrm{H}_{x} \mathrm{dhtp}$ and $\mathrm{Co}(\mathrm{II})$ to form than with $\mathrm{Ni}(\mathrm{II})$. However, previous reports (and our own observations from the in-situ powder X-ray diffraction experiments) indicate that CPO-27-Co forms faster than CPO-27-Ni. ${ }^{42,48}$ Comprehensive lists of species observed and the assignments are listed in Tables S3 and S4 for Ni and Co, respectively.

Complementary high resolution ESI-MS spectra were recorded, and the same $\left\{\mathrm{Ni}\left(\mathrm{H}_{x} \mathrm{dhtp}\right)\right\}$ species (albeit in hydrated form) are found. Additionally, species assigned to complexes of Ni, acetate and solvent adducts are present, see Figure S11 and Table S9. The lower intensity species have been assigned to solvated $\left\{\mathrm{Ni}_{2}\left(\mathrm{H}_{x} \mathrm{dhtp}\right)\right\},\left\{\mathrm{Ni}_{2}\left(\mathrm{H}_{x} \mathrm{dhtp}\right)_{2}\right\}$ and at yet lower intensity to $\left\{\mathrm{Ni}_{3}\left(\mathrm{H}_{x} \mathrm{dhtp}\right)_{2}\right\}$, all with solvent and/or acetate adducts. Some larger complexes such as $\left\{\mathrm{Ni}_{5}\left(\mathrm{H}_{x} \mathrm{dhtp}\right)_{4}\right\}$ have been identified in the high resolution data, but these are of very low intensity. 
See Table S11 for the corresponding Co-results. To summarise, species assigned to $\left\{M\left(H_{x} d h t p\right)\right\}$ are the most dominant species as soon as the reactants are mixed, followed by $\left\{\mathrm{M}_{2}\left(\mathrm{H}_{x} \mathrm{dhtp}\right)\right\}$ species and larger species (of reducing intensity) up to $\left\{\mathrm{M}_{3}\left(\mathrm{H}_{x} \mathrm{dhtp}\right)_{3}\right\}$ complexes, with solvent and/or acetate adducts.

\section{Investigations into the reactions at $110{ }^{\circ} \mathrm{C}$}

At $110^{\circ} \mathrm{C}$, both 1:1 and 2:1 molar ratios of the reactants lead to formation of CPO-27-Ni and -Co, and both of these reactions were investigated. Parallel reactions were set up from the same stock solutions. For Ni, the reactions were stopped at different time intervals and MS were recorded. Aliquots were taken from a few minutes at $110{ }^{\circ} \mathrm{C}$ and up to $24 \mathrm{~h}$, when product formation is complete. Product formation typically starts after about $2 \mathrm{~h}$ at $110^{\circ} \mathrm{C}$. The Co reactions were only investigated by ESI-MS after about 1 day at $110{ }^{\circ} \mathrm{C}$ for comparison to the Ni reactions.

We observe definite changes as the reactants are mixed, but as the reaction continues at $110{ }^{\circ} \mathrm{C}$ there is little to no change to be observed by ESI-MS. The intensity of species containing both metal and $\mathrm{H}_{x} \mathrm{dhtp}$ is typically reduced after $24 \mathrm{~h}$ at $110{ }^{\circ} \mathrm{C}$, as one would expect for product formation leading to a decrease in concentration of the species in solution. Some new features have been observed, but these are of very low intensity, i.e. not playing a major role, and difficult to assign. In one 1:1 Co-reaction $m / z$ 963.8, assigned to $\left[\mathrm{Co}_{3}\left(\mathrm{C}_{8} \mathrm{H}_{4} \mathrm{O}_{6}\right)\left(\mathrm{C}_{8} \mathrm{H}_{5} \mathrm{O}_{6}\right)_{3}\right]^{+}$, seems to appear after $24 \mathrm{~h}$ at $110{ }^{\circ} \mathrm{C}$, however, this species also appears in some initial measurements at very low intensity, where it doesn't change in intensity as the reaction proceeds at $110^{\circ} \mathrm{C}$. Therefore we do not believe this species is playing a major role in the formation of CPO-27-Co. The in-house mass spectra and tables of assignments are shown in Figures S7-S10 and Tables S5-S8, and the complimentary high resolution data is shown in section S3 in the SI. There are differences in the solvation stages of the same species observed between the two different instruments used, but the 
results from both instrument show the mono- and binuclear species $\left\{\mathrm{M}\left(\mathrm{H}_{x} \mathrm{dhtp}\right)\right\}$ and $\left\{\mathrm{M}_{2}\left(\mathrm{H}_{x} \mathrm{dhtp}\right)\right\}$ as the most abundant of the metal species assigned to contain $\mathrm{H}_{x} \mathrm{dhtp}$. For the Co reactions, species assigned to $\left\{\mathrm{M}_{2}\left(\mathrm{H}_{x} \mathrm{dhtp}\right)\right\}$ are sometimes almost equal in intensity to species assigned to $\left\{\mathrm{M}\left(\mathrm{H}_{x} \mathrm{dhtp}\right)\right\}$. The fact that the ESI-MS spectra remain essentially unchanged over time upon heating strongly indicate that the mono- and dinuclear species $\left\{\mathrm{M}\left(\mathrm{H}_{x} \mathrm{dhtp}\right)\right\}$ and $\left\{\mathrm{M}_{2}\left(\mathrm{H}_{x} \mathrm{dhtp}\right)\right\}$ are the key molecular building units in the synthesis of CPO-27-Ni and -Co.

Tandem mass spectrometry (MS/MS) was employed to confirm the assignments of the different species reported herein. The results together with experimental results from the mixture of $\mathrm{H}_{4} \mathrm{dhtp}$ and $\mathrm{MCl}_{2} \cdot 6 \mathrm{H}_{2} \mathrm{O}$ successfully confirmed the assignments of $m / z 236.9 / 237.9,254.9 / 255.9$ to be $\left[\mathrm{M}\left(\mathrm{C}_{8} \mathrm{H}_{3} \mathrm{O}_{5}\right)\right]^{+}$and $\left[\mathrm{M}\left(\mathrm{C}_{8} \mathrm{H}_{5} \mathrm{O}_{6}\right)\right]^{+}$(see section 4 in the $\left.\mathrm{SI}\right)$.

Investigations at room temperature by ESI-MS. We also investigated the behaviour of the same reaction mixtures at room temperature over a minimum of a two week period by in-house ESI-MS. We again observe clear changes immediately after the reactants are mixed, and then as the reaction proceeds the ESI-MS spectra remain the same, even when precipitate started forming after a couple of days, see section S5 in the SI. Analysis of the microcrystalline materials formed in the 2:1 Ni reactions, and in the 1:1 Ni and Co reactions, were found to be a structure of 1D chains based on $\left[\left(\mathrm{M}\left(\mathrm{H}_{2} \mathrm{dhtp}\right)\left(\mathrm{H}_{2} \mathrm{O}\right)_{4}\right) \cdot 2 \mathrm{H}_{2} \mathrm{O}\right]$, see bottom of Figure 1. Additional information is available in section 7 in the SI. The same chain structure, but with DMSO and $\mathrm{H}_{2} \mathrm{O}$ as solvate molecules, has been reported previously. ${ }^{49}$

The 2:1 Co reactions resulted in larger needle-shaped pink crystals. The compound was confirmed by PXRD analysis to be solvated CPO-27-Co, see comparison in Figure S15. This highlights a significant difference in the behaviour of the nickel and cobalt cations, which was unexpected considering how similar the two metals have behaved otherwise. Osta et al. compared 
the synthesis of CPO-27-Ni and -Co in $2013,{ }^{42}$ where they conclude that the Co-material crystallises more rapidly than the Ni-analogue, and perhaps this might be one of the reasons why we see this difference in behaviour. The yield of the $1: 1$ reactions are around $50 \%$ for both cobalt and nickel, whilst the 2:1 reactions result in yields as low as $10 \%$ for both. Larger yields can be obtained, but typically with $\mathrm{H}_{4} \mathrm{dhtp}$ impurities.

Importantly, despite these reactions resulting in different crystalline products, the ESI-MS analysis show close to identical species in solution for the initial mixture and while the product forms, with the previously identified $\left\{\mathrm{M}\left(\mathrm{H}_{x} \mathrm{dhtp}\right)\right\}$ and $\left\{\mathrm{M}_{2}\left(\mathrm{H}_{x} \mathrm{dhtp}\right)\right\}$ species being the key species present in solution. It is straightforward to anticipate that the key species in solution contribute most to the crystal growth as they are incorporated into the product. In this case, it means the same species, the mononuclear species, $\left\{\mathrm{M}\left(\mathrm{H}_{x} \mathrm{dhtp}\right)\right\}$, and, possibly to a lesser extent, the dinuclear species $\left\{\mathrm{M}_{2}\left(\mathrm{H}_{x} \mathrm{dhtp}\right)\right\}$, play the key role in the crystal growth of both the CPO-27 structure with its condensed metal-oxygen polyhedra and the 1D network $\left[\mathrm{M}\left(\mathrm{H}_{2} \mathrm{dhtp}\right)\left(\mathrm{H}_{2} \mathrm{O}\right)_{4}\right]$ with isolated metal cations. Larger intermediate species are not observed as major solutes in the ESI-MS, which we interpret to mean that nucleation and crystal growth from the mono- and dinuclear species apparently occur so rapidly that larger species play no significant role in the crystal growth.

Synchrotron investigations. An in-situ, time resolved powder diffraction study of the formation of CPO-27-Ni was carried out. A 2:1 molar ratio reaction of $\mathrm{Ni}(\mathrm{OAc})_{2} \cdot 4 \mathrm{H}_{2} \mathrm{O}$ and $\mathrm{H}_{4} \mathrm{dhtp}$ in 1:1 (v:v) $\mathrm{H}_{2} \mathrm{O}$ and THF was prepared in a sealed capillary $(0.5 \mathrm{~mm})$, and inserted into the X-ray beam. A heat gun was employed to heat the reaction from room temperature to $110^{\circ} \mathrm{C}$ with $5{ }^{\circ} \mathrm{C} \mathrm{min}^{-1}$, with X-ray data being collected simultaneously. There were no diffraction peaks to be observed at time 0 (scan 1), meaning there is nothing crystalline present in the reaction mixture at this stage. 
There are no diffraction peaks present before we reach $110^{\circ} \mathrm{C}$ (scan no. 12), at which point we observe a rapid increase in the intensity of the (110) and (030) reflections, as can be seen in Figure 4. These two reflections are typical for the CPO-27-Ni structure. In accordance with previously reported results, we can confirm that for the $\mathrm{CPO}-27-\mathrm{Ni}$ structure there is no intermediate crystalline species forming in the reaction solution between $\mathrm{Ni}(\mathrm{OAc})_{2} \cdot 4 \mathrm{H}_{2} \mathrm{O}$ and $\mathrm{H}_{4} \mathrm{dhtp}$. This is an agreement with recent time-resolved PXRD-results, which showed that the crystallite formation of ZIF-8 is already complete after $8 \mathrm{~s}$ of reaction time. ${ }^{50}$ As the reaction continues, the complete PXRD pattern expected for hydrated CPO-27-Ni is clearly observed.

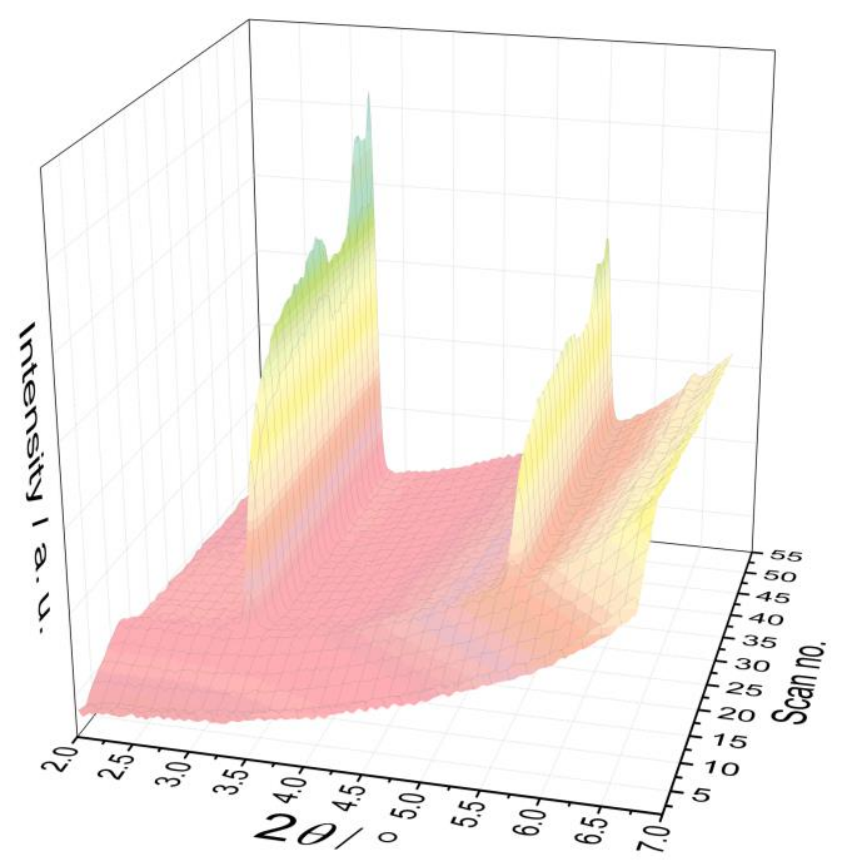

Figure 4. Synchrotron PXRD data, observing the formation of CPO-27-Ni in a capillary experiment. The observed dip in intensity occurs because the suspension is no longer homogenous (the crystals get larger and start to move around inside the capillary, resulting in variation in the amount being irradiated by the beam).

The full width at half maximum (FWHM) of the first two reflection peaks decrease quickly (see SI section 8) as the initially formed crystallites start growing as soon as the concentration of 
reactants in the reaction mixture has decreased below the level leading to the initial nucleation. Similar observations have been reported by Osta et al., where they observed a longer nucleation time for $\mathrm{Ni}$ in comparison with $\mathrm{Co}^{42}$ This was also consistent with previous reports by Haque et $a l .,{ }^{48}$ where they proposed the difference was due to the higher lability of $\left[\mathrm{Co}\left(\mathrm{H}_{2} \mathrm{O}\right)_{6}\right]^{2+}$, which is responsible for the enhanced rate of reaction with the carboxylate ligand via increased solventligand exchange kinetics.

\section{DISCUSSION}

The time resolved powder diffraction study confirms that the first crystalline product observed is CPO-27-M $(\mathrm{M}=\mathrm{Co}, \mathrm{Ni})$, as evidenced by the two strong diffraction peaks appearing a few minutes after the reaction mixture reached a temperature of $110^{\circ} \mathrm{C}$. The crystallisation at room temperature resulted in a $1 \mathrm{D}$ chain structure from the $2: 1$ and $1: 1$ molar ratios Ni reactions, and 1:1 molar ratio Co reactions, whilst the 2:1 molar ratio Co reactions result in the CPO-27-Co structure. Clear changes were observed by ESI-MS when the reactants were mixed, and then as the reactions proceeded at room temperature little to no changes was observed, not even when precipitate started forming. Finally, the MS spectra of the $110^{\circ} \mathrm{C}$ reactions were also very similar to those observed for the reactions at room temperature. We conclude based on these observations that the species present in the reaction mixture do not change significantly as the crystallisation proceeds and the solid product is formed. These species also represent the building blocks from which the metalorganic framework is constructed.

From the extensive ESI-MS analyses carried out herein, we know that the spectra change significantly as soon as the reactants are mixed. In the spectra, the $\left\{\mathrm{M}\left(\mathrm{H}_{x} \mathrm{dhtp}\right)\right\}$ species are most evident, followed by the $\left\{\mathrm{M}_{2}\left(\mathrm{H}_{x} \mathrm{dhtp}\right)_{2}\right\}$ species, as well as metal-complexes containing only 
acetate and/or solvent molecules. Because we observe these $\left\{\mathrm{M}\left(\mathrm{H}_{x} \mathrm{dhtp}\right)\right\}$ and $\left\{\mathrm{M}_{2}\left(\mathrm{H}_{x} \mathrm{dhtp}\right)_{2}\right\}$ species so clearly and of significant intensity in the spectra from both ESI-MS instruments, these species are likely the key building blocks in the formation of CPO-27-M, as well as for the 1D $\left[\left(\mathrm{M}\left(\mathrm{H}_{2} \mathrm{dhtp}\right)\left(\mathrm{H}_{2} \mathrm{O}\right)_{4}\right) \cdot 2 \mathrm{H}_{2} \mathrm{O}\right]$ structure. The metal to $\mathrm{H}_{x}$ dhtp ratio in the final CPO-27-M structure is $2: 1$; thus, in addition to the $\left\{\mathrm{M}\left(\mathrm{H}_{x} \mathrm{dhtp}\right)\right\}$ and $\left\{\mathrm{M}_{2}\left(\mathrm{H}_{x} \mathrm{dhtp}\right)\right\}$ species, metal-complexes of $\mathrm{M}_{1}$ with solvent and/or acetate adducts, which are always present in the ESI-MS analysis, are also involved in the crystallisation process.

Larger, more complex species were observed by ESI-MS, but at very low intensities. These species are either product of the ionisation, or larger species are also present in the reaction mixture. However, if there were significant amounts of larger species (up to $\mathrm{m} / \mathrm{z} 2500$ ) present in the solution, they are expected to be visible with significant intensity in the spectra recorded using the high resolution ESI-MS. As this is not the case we conclude that the initial solid nuclei that are too heavy to be observable using the ESI-MS technique (i.e. cannot be sufficiently ionised into the gas phase) have assembled rapidly from the smaller species present in solution. Further crystal growth then occurs by addition of smaller species to the present nuclei and crystallites. We propose that these smaller $\left\{\mathrm{M}\left(\mathrm{H}_{x} \mathrm{dhtp}\right)\right\}$ and $\left\{\mathrm{M}_{2}\left(\mathrm{H}_{x} \mathrm{dhtp}\right)\right\}$ species together with $\mathrm{M}_{1}$ solvent and/or acetate complexes are the key building blocks for the final crystalline compound. In any of these, one metal centre coordinates a maximum of two $\mathrm{H}_{x} \mathrm{dhtp}$ units, and it is interesting to note that the same species are typically observed independent of the final product being CPO-27-M or $\left[\left(\mathrm{M}\left(\mathrm{H}_{2} \mathrm{dhtp}\right)\left(\mathrm{H}_{2} \mathrm{O}\right)_{4}\right) \cdot 2 \mathrm{H}_{2} \mathrm{O}\right]$, which is a strong argument for smaller species being a key part of the formation of both materials. Serre et al. have reported an X-ray study where they identified discrete, fully formed secondary building units (SBUs) present prior to the formation of the MOF known as MIL-89. ${ }^{51}$ Henderson et al. also found that ESI-MS as a technique is useful in the 
identification of stable SBUs prior to crystal growth. ${ }^{13,19}$ It is not possible to identify such SBUs for the CPO-27 structure due to the nature of the infinite chain-structure, and can explain why we do not observe larger species during the formation of CPO-27-M.

\section{CONCLUSIONS}

A better understanding of the elusive self-assembly processes can contribute to address the challenge of preparing new, robust MOFs with desired properties for specific applications. A part of this understanding is improved insight into the species present under reaction conditions and reactions occurring in the solution on the molecular level.

Here, we have performed an investigation into the formation of CPO-27-Ni and -Co utilising electrospray ionisation mass spectrometry (ESI-MS). Time resolved PXRD analyses do not show any intermediary crystalline species except $\mathrm{CPO}-27-\mathrm{M}(\mathrm{M}=\mathrm{Co}, \mathrm{Ni})$ during the reaction and the product formation starts within minutes when the reaction is kept at $110^{\circ} \mathrm{C}$. When the reaction is followed using ESI-MS, clear changes were observed in the spectra as the reactants were mixed, but as the reaction continued, the spectra remained very similar. The fact that there were hardly no development of species observed by ESI-MS over time as the reactions proceeded was unexpected and indicates that the species in solution are more rapidly incorporated into the growing crystallite rather than forming species with multiple cations in solution. We have identified the mono- and dinuclear species $\left\{\mathrm{M}\left(\mathrm{H}_{x} \mathrm{dhtp}\right)\right\}$ and $\left\{\mathrm{M}_{2}\left(\mathrm{H}_{x} \mathrm{dhtp}\right)\right\}$ as key linker-containing building blocks in the formation of CPO-27-M, as well as in the formation of the 1D chain structure $\left[\left(\mathrm{M}\left(\mathrm{H}_{2} \mathrm{dhtp}\right)\left(\mathrm{H}_{2} \mathrm{O}\right)_{4} \cdot 2 \mathrm{H}_{2} \mathrm{O}\right]\right.$ obtained from room temperature reactions. 


\section{ASSOCIATED CONTENT}

The following files are available free of charge.

Supporting Information: Further details on ESI-MS experiments and assignments, along with crystallographic details (PDF).

Accession code: CCDC 1499898 contain the supplementary crystallographic data for this paper.

These data can be obtained free of charge via www.ccdc.cam.ac.uk/ data_request/cif, or by emailing data_request@eccdc.cam.ac.

\section{AUTHOR INFORMATION}

\section{Corresponding Author}

*(M.H.R.) E-mail: mali.rosnes@uib.no.

*(P.D.C.D) E-mail: Pascal.Dietzel@uib.no.

\section{ORCID}

Mali Husby Rosnes: 0000-0003-3274-9967

Pascal D. C. Dietzel: 0000-0001-5731-2118

Karl Wilhelm Törnroos: 0000-0001-6140-5915

Rune E. Johnsen: 0000-0002-9929-6942

Notes.

The authors declare no competing financial interest 


\section{Author Contributions}

The manuscript was written through contributions of all authors. All authors have given approval to the final version of the manuscript.

\section{ACKNOWLEDGMENT}

The authors would like to thank Dr Bjarte Holmelid and acknowledge the support from the Research Council of Norway through the FRINATEK program (grant 221596). We also want to thank the staff at the Swiss-Norwegian Beamlines at ESRF.

\section{REFERENCES}

(1) Saha, R.; Joarder, B.; Roy, A. S.; Manirul Islam, S.; Kumar, S. Simultaneous Presence of Both Open Metal Sites and Free Functional Organic Sites in a Noncentrosymmetric Dynamic Metal-Organic Framework with Bimodal Catalytic and Sensing Activities. Chem. - Eur. J. 2013, 19, 16607-16614.

(2) Xamena, F. L. i.; Gascon, J., Metal Organic Frameworks as Heterogeneous Catalysts. Royal Society of Chemistry: Cambridge, 2013.

(3) Yu, D.; Yazaydin, A. O.; Lane, J. R.; Dietzel, P. D. C.; Snurr, R. Q. A combined experimental and quantum chemical study of $\mathrm{CO} 2$ adsorption in the metal-organic framework CPO-27 with different metals. Chem. Sci. 2013, 4, 3544-3556.

(4) Mathieson, J. S.; Cooper, G. J. T.; Pickering, A. L.; Keller, M.; Long, D.-L.; Newton, G. N.; Cronin, L. Monitoring the Formation of Coordination Complexes Using Electrospray Mass Spectrometry. Chem. - Asian J. 2009, 4, 681-687.

(5) Mathieson, J. S.; Rosnes, M. H.; Sans, V.; Kitson, P. J.; Cronin, L. Continuous parallel ESI-MS analysis of reactions carried out in a bespoke 3D printed device. Beilstein J. Nanotechnol. 2013, 4, 285-291.

(6) Hirsch, K. A.; Wilson, S. R.; Moore, J. S. Association of Dicyanodiphenylacetylenes with Silver(I) Salts in Solution and Solid State: Electrospray Ionization Mass Spectrometry Samples Aggregates at Subsaturated Concentrations. J. Am. Chem. Soc. 1997, 119, 10401-10412.

(7) Yang, H.-B.; Northrop, B. H.; Zheng, Y.-R.; Ghosh, K.; Lyndon, M. M.; Muddiman, D. C.; Stang, P. J. Synthesis of Six-Component Metallodendrimers via [3 + 3] CoordinationDriven Self-Assembly. J. Org. Chem. 2009, 74, 3524-3527.

(8) Wilson, E. F.; Miras, H. N.; Rosnes, M. H.; Cronin, L. Real-Time Observation of the Self-Assembly of Hybrid Polyoxometalates Using Mass Spectrometry. Angew. Chem., Int. Ed. 2011, 50, 3720-3724.

(9) Rosnes, M. H.; Musumeci, C.; Pradeep, C. P.; Mathieson, J. S.; Long, D.-L.; Song, Y.-F.; Pignataro, B.; Cogdell, R.; Cronin, L. Assembly of Modular Asymmetric Organic-Inorganic Polyoxometalate Hybrids into Anisotropic Nanostructures. J. Am. Chem. Soc. 2010, 132, 15490-15492. 
(10) Wilson, E. F.; Abbas, H.; Duncombe, B. J.; Streb, C.; Long, D.-L.; Cronin, L. Probing the Self-Assembly of Inorganic Cluster Architectures in Solution with Cryospray Mass Spectrometry: Growth of Polyoxomolybdate Clusters and Polymers Mediated by Silver(I) Ions. J. Am. Chem. Soc. 2008, 130, 13876-13884.

(11) Seeber, G.; Cooper, G. J. T.; Newton, G. N.; Rosnes, M. H.; Long, D.-L.; Kariuki, B. M.; Kogerler, P.; Cronin, L. Following the self assembly of supramolecular MOFs using Xray crystallography and cryospray mass spectrometry. Chem. Sci. 2010, 1, 62-67.

(12) Garibay, S. J.; Wang, Z.; Tanabe, K. K.; Cohen, S. M. Postsynthetic Modification: A Versatile Approach Toward Multifunctional Metal-Organic Frameworks. Inorg. Chem. 2009, 48, 7341-7349.

(13) Rood, J. A.; Boggess, W. C.; Noll, B. C.; Henderson, K. W. Assembly of a Homochiral, Body-Centered Cubic Network Composed of Vertex-Shared Mg12 Cages: Use of Electrospray Ionization Mass Spectrometry to Monitor Metal Carboxylate Nucleation. $J$. Am. Chem. Soc. 2007, 129, 13675-13682.

(14) Lim, I. H.; Schrader, W.; Schüth, F. Insights into the Molecular Assembly of Zeolitic Imidazolate Frameworks by ESI-MS. Chem. Mater. 2015, 27, 3088-3095.

(15) Lim, I. H.; Schrader, W.; Schüth, F. The formation of zeolites from solution - Analysis by mass spectrometry. Microporous Mesoporous Mater. 2013, 166, 20-36.

(16) Wagia, R.; Strashnov, I.; Anderson, M. W.; Attfield, M. P. Determination of the Preassembled Nucleating Units That Are Critical for the Crystal Growth of the MetalOrganic Framework CdIF-4. Angew. Chem., Int. Ed. 2016, 55, 9075-9079.

(17) Terban, M. W.; Banerjee, D.; Ghose, S.; Medasani, B.; Shukla, A.; Legg, B. A.; Zhou, Y.; Zhu, Z.; Sushko, M. L.; De Yoreo, J. J.; Liu, J.; Thallapally, P. K.; Billinge, S. J. L. Early stage structural development of prototypical zeolitic imidazolate framework (ZIF) in solution. Nanoscale 2018, 10, 4291-4300.

(18) Rosnes, M. H.; Nesse, F. S.; Opitz, M.; Dietzel, P. D. C. Morphology control in modulated synthesis of metal-organic framework CPO-27. Microporous Mesoporous Mater. 2019, 275, 207-213.

(19) Rood, J. A. Metal-Organic Frameworks as Functional, Porous Materials. University of Notre Dame, Notre Dame, Indiana, 2009.

(20) Dietzel, P. D. C.; Morita, Y.; Blom, R.; Fjellvåg, H. An In Situ High-Temperature SingleCrystal Investigation of a Dehydrated Metal-Organic Framework Compound and FieldInduced Magnetization of One-Dimensional Metal-Oxygen Chains. Angew. Chem., Int. Ed. 2005, 44, 6354-6358.

(21) Dietzel, P. D. C.; Panella, B.; Hirscher, M.; Blom, R.; Fjellvåg, H. Hydrogen adsorption in a nickel based coordination polymer with open metal sites in the cylindrical cavities of the desolvated framework. Chem. Commun. 2006, 959-961.

(22) Dietzel, P. D. C.; Blom, R.; Fjellvåg, H. Base-Induced Formation of Two Magnesium Metal-Organic Framework Compounds with a Bifunctional Tetratopic Ligand. Eur. J. Inorg. Chem. 2008, 2008, 3624-3632.

(23) Zhou, W.; Wu, H.; Yildirim, T. Enhanced H2 Adsorption in Isostructural Metal-Organic Frameworks with Open Metal Sites: Strong Dependence of the Binding Strength on Metal Ions. J. Am. Chem. Soc. 2008, 130, 15268-15269.

(24) Rosi, N. L.; Kim, J.; Eddaoudi, M.; Chen, B.; O'Keeffe, M.; Yaghi, O. M. Rod Packings and Metal-Organic Frameworks Constructed from Rod-Shaped Secondary Building Units. J. Am. Chem. Soc. 2005, 127, 1504-1518. 
(25) Bloch, E. D.; Murray, L. J.; Queen, W. L.; Chavan, S.; Maximoff, S. N.; Bigi, J. P.; Krishna, R.; Peterson, V. K.; Grandjean, F.; Long, G. J.; Smit, B.; Bordiga, S.; Brown, C. M.; Long, J. R. Selective Binding of O2 over N2 in a Redox-Active Metal-Organic Framework with Open Iron(II) Coordination Sites. J. Am. Chem. Soc. 2011, 133, 1481414822.

(26) Märcz, M.; Johnsen, R. E.; Dietzel, P. D. C.; Fjellvåg, H. The iron member of the CPO27 coordination polymer series: Synthesis, characterization, and intriguing redox properties. Microporous Mesoporous Mater. 2012, 157, 62-74.

(27) Calleja, G.; Sanz, R.; Orcajo, G.; Briones, D.; Leo, P.; Martínez, F. Copper-based MOF74 material as effective acid catalyst in Friedel-Crafts acylation of anisole. Catal. Today 2014, 227, 130-137.

(28) Sanz, R.; Martínez, F.; Orcajo, G.; Wojtas, L.; Briones, D. Synthesis of a honeycomb-like $\mathrm{Cu}$-based metal-organic framework and its carbon dioxide adsorption behaviour. Dalton Trans. 2013, 42, 2392-2398.

(29) Rosnes, M. H.; Opitz, M.; Frontzek, M.; Lohstroh, W.; Embs, J. P.; Georgiev, P. A.; Dietzel, P. D. C. Intriguing differences in hydrogen adsorption in CPO-27 materials induced by metal substitution. J. Mater. Chem. A 2015, 3, 4827-4839.

(30) Díaz-García, M.; Sánchez-Sánchez, M. Synthesis and characterization of a new Cd-based metal-organic framework isostructural with MOF-74/CPO-27 materials. Microporous Mesoporous Mater. 2014, 190, 248-254.

(31) Valvekens, P.; Vandichel, M.; Waroquier, M.; Van Speybroeck, V.; De Vos, D. Metaldioxidoterephthalate MOFs of the MOF-74 type: Microporous basic catalysts with welldefined active sites. J. Catal. 2014, 317, 1-10.

(32) Dietzel, P. D. C.; Besikiotis, V.; Blom, R. Application of metal-organic frameworks with coordinatively unsaturated metal sites in storage and separation of methane and carbon dioxide. J. Mater. Chem. 2009, 19, 7362-7370.

(33) Caskey, S. R.; Wong-Foy, A. G.; Matzger, A. J. Dramatic Tuning of Carbon Dioxide Uptake via Metal Substitution in a Coordination Polymer with Cylindrical Pores. J. Am. Chem. Soc. 2008, 130, 10870-10871.

(34) Dietzel, P. D. C.; Johnsen, R. E.; Fjellvåg, H.; Bordiga, S.; Groppo, E.; Chavan, S.; Blom, R. Adsorption properties and structure of $\mathrm{CO} 2$ adsorbed on open coordination sites of metal-organic framework Ni2(dhtp) from gas adsorption, IR spectroscopy and X-ray diffraction. Chem. Commun. 2008, 5125-5127.

(35) Burtch, N. C.; Jasuja, H.; Walton, K. S. Water Stability and Adsorption in Metal-Organic Frameworks. Chem. Rev. 2014, 114, 10575-10612.

(36) Ramanan, A.; Whittingham, M. S. How Molecules Turn into Solids: the Case of SelfAssembled Metal-Organic Frameworks. Cryst. Growth Des. 2006, 6, 2419-2421.

(37) Stock, N.; Reinsch, H.; Schillinger, L.-H., Synthesis of MOFs. In Metal Organic Frameworks as Heterogenous Catalysts, Xamena, F. X. L. i.; Gascon, J., Eds. Henry Ling Limited: Dorchester, 2013.

(38) Guasch, J.; Dietzel, P. D. C.; Collier, P.; Acerbi, N. The effect of solvent and temperature in the synthesis of CPO-27-Ni by reflux. Microporous Mesoporous Mater. 2015, 203, 238-244.

(39) Garzon-Tovar, L.; Carne-Sanchez, A.; Carbonell, C.; Imaz, I.; Maspoch, D. Optimised room temperature, water-based synthesis of CPO-27-M metal-organic frameworks with high space-time yields. J. Mater. Chem. A 2015, 3, 20819-20826. 
(40) Stavitski, E.; Goesten, M.; Juan-Alcañiz, J.; Martiñez-Joaristi, A.; Serra-Crespo, P.; Petukhov, A. V.; Gascon, J.; Kapteijn, F. Kinetic Control of Metal-Organic Framework Crystallization Investigated by Time-Resolved In Situ X-Ray Scattering. Angew. Chem., Int. Ed. 2011, 50, 9624-9628.

(41) Millange, F.; Medina, M. I.; Guillou, N.; Férey, G.; Golden, K. M.; Walton, R. I. TimeResolved In Situ Diffraction Study of the Solvothermal Crystallization of Some Prototypical Metal-Organic Frameworks. Angew. Chem., Int. Ed. 2010, 49, 763-766.

(42) Osta, R. E.; Feyand, M.; Stock, N.; Millange, F.; Walton, R. I. Crystallisation Kinetics of Metal Organic Frameworks From in situ Time-Resolved X-ray Diffraction. Powder Diffr. 2013, 28, S256-S27S.

(43) Yeung, H. H. M.; Wu, Y.; Henke, S.; Cheetham, A. K.; O'Hare, D.; Walton, R. I. In Situ Observation of Successive Crystallizations and Metastable Intermediates in the Formation of Metal-Organic Frameworks. Angew. Chem., Int. Ed. 2016, 55, 2012-2016.

(44) Wu, Y.; Moorhouse, S. J.; O’Hare, D. Time-Resolved in Situ Diffraction Reveals a SolidState Rearrangement During Solvothermal MOF Synthesis. Chem. Mater. 2015, 27, 7236-7239.

(45) Jolivet, J.-P., Metal Oxide Chemistry and Synthesis - From Solution to Solid State. John Wiley Sons Ltd.: Chichester, UK, 2000.

(46) Hammersley, A. P.; Svensson, S. O.; Hanfland, M.; Fitch, A. N.; Hausermann, D. Twodimensional detector software: From real detector to idealised image or two-theta scan. High Pressure Res. 1996, 14, 235-248.

(47) McDonald, L. W.; Campbell, J. A.; Clark, S. B. Failure of ESI Spectra to Represent Metal-Complex Solution Composition: A Study of Lanthanide-Carboxylate Complexes. Anal. Chem. 2014, 86, 1023-1029.

(48) Haque, E.; Jhung, S. H. Synthesis of isostructural metal-organic frameworks, CPO-27s, with ultrasound, microwave, and conventional heating: Effect of synthesis methods and metal ions. Chem. Eng. J. 2011, 173, 866-872.

(49) Rosa, I. M. L.; Costa, M. C. S.; Vitto, B. S.; Amorim, L.; Correa, C. C.; Pinheiro, C. B.; Doriguetto, A. C. Influence of Synthetic Methods in the Structure and Dimensionality of Coordination Polymers. Cryst. Growth Des. 2016, 16, 1606-1616.

(50) Polyzoidis, A.; Etter, M.; Herrmann, M.; Loebbecke, S.; Dinnebier, R. E. Revealing the Initial Reaction Behavior in the Continuous Synthesis of Metal-Organic Frameworks Using Real-Time Synchrotron X-ray Analysis. Inorg. Chem. 2017, 56, 5489-5492.

(51) Surble, S.; Millange, F.; Serre, C.; Ferey, G.; Walton, R. I. An EXAFS study of the formation of a nanoporous metal-organic framework: evidence for the retention of secondary building units during synthesis. Chem. Commun. 2006, 1518-1520. 


\section{For Table of Contents Use Only}

Title: An Electrospray Mass Spectrometry Investigation into the Formation of CPO-27

Authors: Mali H. Rosnes, Jennifer S. Mathieson, Karl W. Törnroos, Rune E. Johnsen, Leroy Cronin and Pascal D. C. Dietzel

TOC graphic:

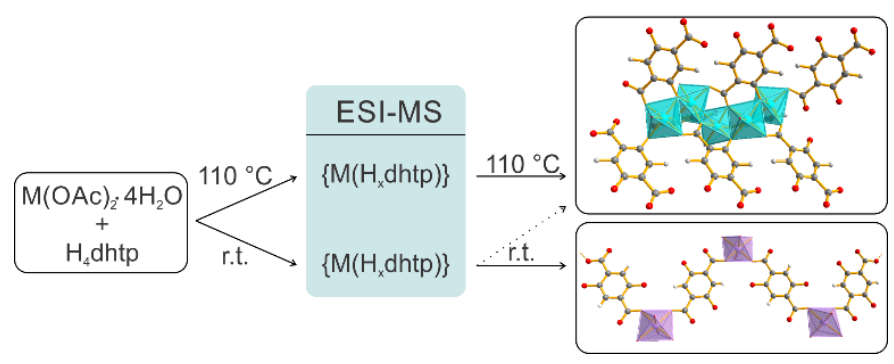

SYNOPSIS: For the first time, electrospray ionisation mass spectrometry (ESI-MS) has been utilised to investigate the self-assembly processes governing the formation of the microporous metal-organic framework CPO-27-M. The mono- and dinuclear species $\left\{\mathrm{M}\left(\mathrm{H}_{x} \mathrm{dhtp}\right)\right\}$ and $\left\{\mathrm{M}_{2}\left(\mathrm{H}_{x} \mathrm{dhtp}\right)\right\}$ have been identified as key building blocks in the formation of CPO-27-M. 